\title{
Relationship between Neurocognitive Performance and Body Composition of Men and Women Exposed to Organic Solvents
}

\author{
Ana Raquel Oliveira*,1 \\ Orcid.org/0000-0002-9989-0255 \\ Thayro Andrade Carvalho ${ }^{2}$ \\ Orcid.org/0000-0001-5107-0074 \\ Natanael Antonio dos Santos ${ }^{3}$ \\ Orcid.org/0000-0001-7708-9929
}

\author{
${ }^{1}$ Universidade Federal do Piauí, Teresina, PI, Brasil \\ ${ }^{2}$ Universidade Federal do Rio Grande do Norte, Natal, RN, Brasil \\ ${ }^{3}$ Universidade Federal da Paraíba, João Pessoa, PB, Brasil
}

\begin{abstract}
It was investigate the effect of organic solvents on the neurocognitive performance of men and women with and without chronic exposure to organic solvents and verify correlations between neurocognitive performance and body composition indices. Participants included 14 men and 14 exposed women and 14 men and 14 unexposed women. The Trail Making Test (TMT) A and B, the Rey Complex Figure (RCF; Copy and Memory), sociodemographic questionnaire, and bioimpedance evaluation were used. There was a significant difference between exposed and non-exposed women in all tests. Comparison between exposed and non-exposed men showed a significant difference in TMT-A, RCF-Copy, and RCF-Memory. However, there was no significant difference between sexes. Regarding the comparison between neurocognitive performance and body composition indices, for exposed women, there was a significant correlation between RCF- Copy and water, body weight, fat mass, and lean mass. Regarding the exposed men, there was a significant correlation between TMT-B and WHR (waist-hip ratio) and visceral fat. In general, organic solvents can affect neurocognitive performance and the effects of chronic exposure depend on the accuracy of the neurocognitive test and the body composition index.
\end{abstract}

Keywords: Attention, memory, executive functions, organic solvents, body composition, sexes.

\section{Relação entre Desempenho Neurocognitivo e Composição Corporal de Homens e Mulheres Expostos a Solventes Orgânicos}

\section{Resumo}

Investigou-se o efeito dos solventes orgânicos sobre o desempenho neurocognitivo de homens e mulheres com e sem exposição crônica a solventes orgânicos, e verificou correlações entre o desempenho

* Mailing address: Universidade Federal do Piauí, Departamento de Fundamentos da Educação, Campus Ministro Petrônio Portella, s/n, Ininga, Teresina, PI, Brazil 64049-550. Phone: (86) 3215-5513. E-mail: anaraqueloliveira@hotmail.com, thayrocarvalho@gmail.com and natanael_labv@yahoo.com.br 
neurocognitivo e índices de composição corporal. Participaram 14 homens e 14 mulheres expostos e 14 homens e 14 mulheres não expostos. Utilizou-se o Trail Making Test (TMT) A e B, Figura Complexa de Rey (FCR), Cópia e Memória, questionário sociodemográfico e avaliação de bioimpedância. A comparação entre mulheres expostas e não expostas mostrou diferença significativa em todos os testes. A comparação entre os homens expostos e não expostos mostrou diferença significativa no TMT-A, FCRCópia, FCR-Memória. Contudo, na comparação entre homens e mulheres expostos os resultados não mostraram diferenças significantes. Já na correlação entre o desempenho neurocognitivo com índices de composição corpórea, as mulheres expostas apresentaram correlação significante entre FCR-Cópia com água corporal, peso, massa gorda, massa magra corporal. Os homens expostos apresentaram correlação significante entre o TMT-B com a Relação Cintura-Quadril e gordura visceral. No geral, os solventes orgânicos podem afetar o desempenho neurocognitivo e os efeitos da exposição crônica dependem da precisão do teste neurocognitivo e do índice de composição corpórea.

Palavras-chave: Atenção, memória, funções executivas, solventes orgânicos, composição corporal, sexos.

\section{Relación entre Desempeño Neurocognitivo y Composición Corporal de Hombres y Mujeres Expuestos a Solventes Orgánicos}

\section{Resumen}

Se investigo el efecto de solventes orgánicos sobre el rendimiento neurocognitivo de hombres y mujeres con y sin exposición crónica a solventes orgánicos, además de verificar la correlación entre el rendimiento neurocognitivo y los índices de composición corporal. Participaron 14 hombres y 14 mujeres expuestas y 14 hombres y 14 mujeres no expuestas. Se utilizaron los siguientes tests: Trail Making Test (TMT) A y B, el test Figura Compleja de Rey (FCR; Copia y Memoria), cuestionario sociodemográfico y la evaluación de bioimpedancia. Hubo diferencia significativa entre las mujeres expuestas y las no expuestas, en todos los tests. La comparación de los hombres expuestos con los que no fueron expuestos mostró diferencia significativa en el TMT-A, FCR-Copia y FCR-Memoria. Sin embargo, no hubo diferencias significativas entre los sexos. Con relación a la comparación del rendimiento neurocognitivo con los índices de composición corporal, para las mujeres expuestas hubo correlación significativa entre la FCR-Copia y el agua, peso, masa corporal grasa y masa corporal magra. Para los hombres expuestos hubo correlación significativa entre la TMT-B y la relación cintura/cadera (RCC) y grasa visceral. En general, los solventes orgánicos pueden afectar el desempeño neurocognitivo y los efectos de la exposición crónica dependen de la precisión del test neurocognitivo y del índice de composición corporal.

Palabras clave: Atención, memoria, funciones ejecutivas, solventes orgánicos, composición corporal, sexos.

Organic solvents are hydrocarbons derived from the distillation of petroleum and used in the composition of paints, cosmetics, degreasers, pesticides and fuels (Occupational Safety and Health Service - OSHS, 1998). These substances are toxic to humans because they are volatile and lipophilic, distributing themselves to organs rich in fat and vascularized tissues such as the brain (Monat-Descamps \& Deschamps, 2012).

Human studies and animal models show that chronic exposure to organic solvents can result in structural changes in the central nervous system (CNS), causing axonal demyelination, neuronal degeneration, and cell loss (Barbosa, 
Boon, \& Khuu, 2015; Lotti, Bleecker, \& Aminoff, 2015), as well as changes in motor, sensory and neurocognitive functions (Morrow \& Scott, 2002; Sabbath et al., 2014). A decline in cognitive ability may be a predictor of the development of a number of neurodegenerative disorders such as dementias, for example (Blazer, Yaffe, \& Liverman, 2015).

Occupational exposure to volatile organic compounds can lead to 35 million cases of disease annually (International Labour Office ILO, 2014). According to the ILO (2014), there were approximately 888,893 thousand deaths in 2011 due to complications from exposure to toxic chemicals, with 1,112 cases resulting from neuropsychiatric conditions (637 women and 475 men).

In recent years, the number of women hired as gas station attendants has increased in most developing countries and in other industrial activities in Western European countries (Ernstgård, Gullstrand, Löf, \& Johanson, 2002). However, most research has been carried out with men (Saygun et al., 2012; Song, Yu, \& Lao, 2015; Thetkathuek, Jaidee, Saowakhontha, \& Ekburanawat, 2015) or male animals (Beasley, Evansky, \& Bushnell, 2012; Zhong et al., 2013), probably because males are still the majority in this type of activity (Vahter et al., 2007), or due to the historical belief that jobs in hazardous environments, including those involving solvents, are restricted to men (Mergler, 2012). These results are eventually generalized to women (Ernstgård et al., 2002) who are exposed to the same tolerance limits based on studies carried out with males (Kawai, Takeuchi, \& Ikeda, 2015).

Physiological and biochemical differences between the sexes have the potential to alter the amount and effects of some solvents on tissues and on health (Klaassen \& Watkins, 2012). Women generally have a higher percentage of adipose tissue, while men have higher muscle mass and body weight (Tseng et al., 2014).

Differences in body composition have raised different points of view about the effects of organic solvents on men and women. From a toxicological point of view, lipophilic solvents accumulate in adipose tissue, and the more body fat the greater the amount and the lower the clearance of chemical agents (Klaassen \& Watkins, 2012). Thus, women could be more sensitive than men to the effects of solvents, as they have a higher percentage of body fat (Gleiter \& Gundert-Remy, 1996).

From the point of view of pharmacokinetics and pharmacodynamics, variations between the sexes such as body weight, plasma volume, and time for gastric emptying may interfere in drug efficacy and toxicity (Gandhi, Aweeka, Greenblatt, \& Blaschke, 2004). Thus, some drugs may have a relatively higher distribution volume and be metabolized more slowly in women compared to men (Soldin \& Mattison, 2009). As lipophilic solvents with high oil-water partition coefficient are distributed and concentrate on body fat, such storage would reduce the concentration of the toxicant in the target tissue; consequently, their toxicity may be less severe in an obese individual than in a lean individual (Klaassen \& Watkins, 2012). According to this perspective, the higher percentage of body fat in women could be a protective factor (Lof \& Johanson, 1998).

Despite this, physiological and biochemical differences between the sexes have not been considered for monitoring exposure to organic solvents (Vahter et al., 2007; Weiss, 2012). Perhaps for this reason few studies have compared the differences between sexes of the neurocognitive effects of exposure to organic solvents in animal (Berenguer, Soulage, Perrin, Pequignot, \& Abraini, 2003; Berr et al., 2010; Malek, Möritz, \& Fanghänel, 2003) and human models (Morrow \& Scott, 2002).

A study with animal models conducted by Malek et al. (2003) compared the performance of 120 LEW.1K rats (males and females) exposed to different concentrations of formaldehyde (0.1 ppm, 0.5ppm, $5.4 \mathrm{ppm}$ ) with non-exposure controls. The experiment used a task that involved learning and memory, and additionally analyzed the histology of some organs. During the experiment the animals inhaled the solvents for two hours/day for ten consecutive days, and the test was performed two hours after the 
exposure. The animal's task was to find the way out of a labyrinth with water. Their time and number of errors were recorded. The researchers observed that the control group required shorter swimming periods and made fewer errors to complete the water labyrinth test compared to the experimental group. A comparison of exposed male and female rats revealed that females generally completed the test in a shorter time than males. However, no differences between sexes regarding number of errors were observed in the group with the highest concentration of formaldehyde (5.4 ppm). The data indicated that formaldehyde can affect learning and memory of male and female rats, even without clinical or histopathological changes. According to Spyker (1979), behavioral changes can be considered as early signs of the body's intoxication processes.

Another study conducted using animal models carried out by Berenguer et al. (2003) investigated the behavioral and neurochemical effects of inhaling $40 \mathrm{ppm}$ of toluene in exposed (6 males and 6 females) and control (6 males and 6 females) Sprague-Dawley rats. The exposed animals were placed in an experimental chamber twice a week (104 hours) for 16 weeks. The results of this study showed that subchronic exposure to toluene: (a) did not alter the locomotor activity of the exposed group of rats compared to the control group. However, the females of both groups presented greater locomotor activity than males; (b) resulted in lower breeding activity in the exposed rats group compared to the control group. However, no significant differences were found between male and female rats in both the control and the exposed groups; (c) resulted in higher sensitivity to narcosis in rats from the exposed group than in the control group, being higher in males of both groups than in females of both groups; and (d) presented an increase of 5-hydroxytryptophan (5-HT) in the hippocampus and prefrontal cortex of exposed females and a decrease of 5-HT and dihydroxyphenylalanine (DOPA) in the hippocampus of exposed males, areas in which this change was not expected. As a rule, the subchronic exposure to $40 \mathrm{ppm}$ of toluene may affect cognitive and behavioral functioning; however, it was not possible to establish a relationship with neurochemical changes.

On the other hand, a study with humans developed by Berr et al. (2010) consisted of a longitudinal study evaluating whether exposure during adulthood was associated with poor neurocognitive performance at the end of middle age. A total of 5,242 volunteers $(4,407$ men) aged 55-65 years participated. Men from the age of 40-50 and women from the age of 35-50 answered a questionnaire, during which time the concentration level of the solvents to which they were exposed to was also monitored. Neurocognitive performance was assessed with the Digit Symbol Substitution Test (DSST) and the Mini Mental State Examination (MMSE). Women performed higher than men on the DSST, however no differences were found in the MMSE. The correlation between test performance and solvent concentration indicated a lower performance on DSST among those with high benzene exposure, and categories of chlorinated, aromatic and petroleum solvents. These data suggest that occupational exposures to solvents may be associated with cognitive impairment during aging.

In order to evaluate neurocognitive performance among sexes after a few months without exposure to organic solvents, Morrow and Scott (2002) compared the results of 17 men and 17 women with chronic exposure (age between 31 and 49 years, average schooling of 13 years and exposure time of 5 years) in the Trail Making Test A, the Rey-Osterrieth complex figure test (ROCF), and the WAIS-R. These authors found no significant differences between sexes $(p>.05)$. However, men and women showed different change patterns as the exposure time significantly affected verbal memory (related to median or temporal structures) of exposed men, and the executive or processing speed (related to more frontal structures) of exposed women.

The objective of the present study was to compare the neurocognitive performance of men and women with and without a history of 
chronic exposure to organic solvents, and to investigate whether there are differences in shortterm memory, attention, and executive functions (cognitive flexibility). Specifically, performance was compared between exposed and non-exposed men; exposed and non-exposed women; and exposed men and women. The main hypothesis was verifying whether chronic exposure to organic solvents impaired neurocognitive functioning. If the main hypothesis were accepted, a second hypothesis was tested to verify whether the effects of chronic exposure to organic solvents could be related to any body composition indices that tend to differentiate between sexes (weight, fat mass, lean body mass, waist-hip ratio, visceral fat and body water).

\section{Method}

\section{Participants}

Fifty-six (56) volunteers distributed into four groups participated in the study: Group of exposed females (GEf), Group of exposed males (GEm), Group of Control Females (GCf), and Group of Control Males (GCm). Sociodemographic data are shown in Table 1.

Table 1

Socio-Demographic Data Regarding Age and Education of Exposed and Control Groups and Exposure Time of Exposed Groups (GEm and GEf) in Years

\begin{tabular}{|c|c|c|c|c|c|c|c|c|c|c|c|c|}
\hline \multirow{2}{*}{ Data } & \multicolumn{2}{|c|}{$\begin{array}{c}\text { GEm } \\
(n=14)\end{array}$} & \multicolumn{2}{|c|}{$\begin{array}{c}\text { GEf } \\
(n=14)\end{array}$} & \multicolumn{2}{|c|}{$\begin{array}{c}\mathrm{GCm} \\
(n=14)\end{array}$} & \multicolumn{2}{|c|}{$\begin{array}{c}\mathrm{GCf} \\
(n=14)\end{array}$} & \multirow[t]{2}{*}{$\chi^{2}$} & \multirow[t]{2}{*}{$p$} & \multirow[t]{2}{*}{$U$} & \multirow[t]{2}{*}{$p$} \\
\hline & $M$ & $S D$ & $M$ & $S D$ & $M$ & $S D$ & $M$ & $S D$ & & & & \\
\hline Age & 29.35 & 5.92 & 28 & 7.05 & 27.50 & 7.81 & 26.36 & 6.26 & 3.81 & .28 & - & - \\
\hline Education & 9.71 & 2.05 & 10.07 & 1.21 & 9.73 & 1.85 & 10.50 & 1.09 & 1.42 & .70 & - & - \\
\hline Exposure & 5.84 & 4.12 & 4.60 & 3.34 & \multicolumn{2}{|c|}{ None } & \multicolumn{2}{|c|}{ None } & - & - & 47.5 & .31 \\
\hline
\end{tabular}

Note. $M=$ mean; $S D=$ standard deviation; GEm = Group of exposed males; GEf = group of exposed females; GCf $=$ Group of Control Females; $\mathrm{GCm}=$ Group of Control Males; $\chi 2=$ Kruskal Wallis test; $U=$ Mann Whitney $U$ Test.

Participants in the study groups were recruited from gas stations upon authorization of the Trade Union of Retail Trade in Petroleum Derivatives, Brazil. Participants from the control groups were recruited from the general population based on an active search and the University researcher headquarter workers were invited and explained the aims and ethical aspects of the study. Those who agreed to participate scheduled a day and time for the data collection.

Participants in the control group were recruited by an active search. The groups were matched by sex, age, and schooling in an attempt to eliminate or reduce the effects of these variables on the results.

Participants included in the four groups had normal or corrected visual acuity (20/20) and agreed to voluntarily participate in the study. In addition, GE were employees who performed the activity of gas station attendants for six months or more (Zavalić, Mandić, Turk, Bogadi-Sare, $\&$ Plavec, 1998), never used personal protective equipment (PPE) such as a mask or glasses, and performed the activity during the morning or evening shift.

Exclusion criteria for the four groups were: consumption of cigarettes, alcoholic beverages or other drugs, exposure to chemical vapors in other professions, ophthalmologic, neurological, psychiatric diseases, diabetes or high blood pressure, regular physical activity, all informed by self-report. Performing at least 30 minutes of physical activity regularly three or more times per week was considered as regular exercise (Bouchard, Blair, \& Haskell, 2012). Intense physical exercise can increase lung uptake of relatively polar solvents and decrease blood flow to the liver and kidneys, thus reducing the bio- 
transformation of metabolized solvents and urinary elimination (Klaassen \& Watkins, 2012).

Participants in the study groups worked morning or evening shifts according to an eighthour shift work schedule, six days/week, with an interval of one hour for lunch. They worked with ethanol, gasoline and diesel.

\section{Instruments}

Clinical and sociodemographic data questionnaire. Aimed to characterize participants according to age, schooling, consumption of alcohol, cigarettes or other drugs, ocular, neurological, psychiatric diseases, diabetes and hypertension, physical activity; and specifically for the GE, exposure time, workload per day and per week (in hours), use of PPE's, and type of material with which they worked or had contact with.

Trail Making Test - TMT (Reitan \& Wolfson, 1985). This instrument assesses attention, cognitive flexibility, visual demand and motor function. The test has two parts, A and B. The participant's task on both sides is to draw a path in the shortest possible time without removing the pencil from the paper. In Part A, participants should trace a line between numbers 1 to 25 , in ascending order. In Part $\mathrm{B}$, there is greater cognitive demand because they must trace a line from numbers 1 to 13 while alternating with the letters A through $\mathrm{L}$, meaning 1-A, 2-B, 3-C and so on. Thus, the TMT-A was administered first, presenting the participant with a shorter sheet/version with the objective of training them to perform the task. The participant was instructed to connect the circles with the numbers in ascending order in the shortest possible time. Then they filled out the "test sheet" and their time was recorded. If an error was made during the test, the volunteer should go back to the previous circle and continue the test (Reitan, 1958). Thus, errors are not recorded, but they increase the total time (Lezak, 2004). The score for this task was the total time in seconds required to connect all the circles. The execution of TMT-B followed the same protocol described for TMT-A, but with the added task of alternately connecting letters to numbers in ascending order.

Rey-Osterrieth Complex Figure Test ROCF (Oliveira, Rigoni, Andretta, \& Moraes, 2004). The Copy and (Memory) Recall phases were used, which evaluate coding and shortterm/immediate recall, respectively. It consists of a card with the drawing of a complex figure composed of a large rectangle, horizontal and vertical bisectors, two diagonals, and additional geometric details internally and externally to the large rectangle. Eighteen (18) items are evaluated and the score for each item can be 0,1 or 2 (one for precision and one for location), with the maximum score corresponding to 36 points. In the copy stage (ROCF-C), the drawing was presented horizontally and the participant copied it onto a blank sheet with no set time. The (Memory) Recall stage (ROCF-M) took place three minutes after the Copy stage. The participant copied the image without looking at the copy or the model. In this interval the participant did not perform any other activity nor were they exposed to distracting stimuli. The neurocognitive tests were corrected according to the manuals' instructions, and the gross score obtained by the participants was taken into account as the objective was to compare the exposed groups to control groups with specific characteristics, which reduced the effects of the results being related to Type I error due to non-control of intervening variables.

Assessment of Body composition. The bioelectrical impedance analysis was performed using the Inbody 720 device (MF-BIA8; Biospace Co. Ltd., Seoul, Korea, 2005). The equipment has an alternating current of 250 milliampere $(\mathrm{mA})$ and a tetrapolar system with eight tactile electrodes, using frequencies in kilohertz $(\mathrm{kHz})$ of $1 ; 5 ; 50 ; 250 ; 500$ and 1000. This equipment verifies the change in impedance in body tissues by sending detectable electrical signals from the body, generating the segmental impedance for the upper and lower limbs and the trunk for all frequencies (Gába \& Přidalová, 2014). The body impedance scores are calculated by summing the segment impedance values. In 
this research, the reference measures taken were: total weight, lean body mass index (LBM), body fat (BF), Waist-to-hip ratio (WHR), visceral fat area, body water.

\section{Procedure}

Neurocognitive assessment and assessment of body composition were performed on different days not exceeding two weeks between one and the other. The neurocognitive evaluation consisted of applying the TMT-A, TMT-B, ROCF Copy and ROCF (Memory) Recall tests, which was performed at the Laboratory of Perception, Neuroscience and Behavior of the Federal University of Paraíba in the city of João Pessoa-PB. All tests were administered by the same psychology professional who was trained over a two-month period by a psychology professor. The overall duration of this evaluation was on average 30 minutes.

The assessment of body composition was performed by a physical educator in the Physical Education laboratory of an Institution of Higher Education in the city of João Pessoa-PB. Participants followed the criteria recommended by the equipment manual before taking the test, for example: not having eaten for a few hours; reducing the volume of urine and feces; remaining standing for five minutes; and for women, not being in their menstrual period. This evaluation lasted an average of ten minutes. Forty-three (43) volunteers participated in this stage, the others claimed schedule incompatibility or dropped out.

\section{Ethical Aspects}

The study was approved by the Ethics Committee of the Federal University of Paraíba with a Certificate of Ethics Presentation Certificate number: 21350113.9.0000.5188. Participation occurred through the signing of the clear and Informed Consent Form, following Resolution 466/12 of the National Health Council (2012) which establishes guidelines and norms regulating research involving human beings.

\section{Data Analysis}

Descriptive and inferential analyzes were performed using the IBM ${ }^{\circledR}$ SPSS ${ }^{\circledR}$ Statistics software version 20.0.0 (IBM Corporation, Armonk, NY, USA). The significance level was set at $p<.05$. Most of the data did not present a normal distribution (KolmogorovSmirnov and Shapiro-Wilk) or homogeneity of variances (Levene's test), possibly due to the small sample size. The non-parametric MannWhitney $U$ analysis was used to compare the performance in the tests between groups: (1) GEf and GCf; (2) GEm and GCm; and (3) GEm and GEf. The effect size was calculated using the Pearson's correlation coefficient $r$, which consists of the following formula: $r=Z / \sqrt{ } N$, in which $Z$ is the standardized score and $N$, the number of observations ( $n=28$; Dancey, Reidy, \& Rowe, 2017). The limit values for the effect size were considered according to Cohen (1988) apud Dancey and Reidy (2013), as small $(0.20-0.49)$, average $(0.50-0.79)$ and large $(\geq 0.80)$.

Spearman $\rho$ analysis was used to correlate measurements of body composition (weight, body fat, lean body mass, waist-hip ratio, visceral fat, body water) with the results obtained in the neurocognitive tests by the male and female study groups. The crude score obtained in the neurocognitive tests for the data analysis were considered.

\section{Results}

\section{Descriptive Analyzes}

Neurocognitive tests. The scores of the TMT-A and TMT-B tests corresponded to the task execution time in seconds, meaning that the shorter the time to complete the task, the better the performance. On the other hand, the test scores for the ROCF-Copy and ROCF-Recall varied according to the precision and good positioning of each item of the drawing, so that the more correct each item was, the better the ability to encode and retrieve the information, respectively. 
Table 2

Descriptive Statistics of the Median, Values of the First and Third Quartiles, Minimum and Maximum obtained in the TMT-A, TMT-B, ROCF-C and ROCF-M Tests for Exposed (GEf, GEm) and Non-Exposed Groups (GCm and GCf)

\begin{tabular}{|c|c|c|c|c|c|c|c|c|c|c|}
\hline \multirow{2}{*}{ Neurocognitive tests } & \multicolumn{5}{|c|}{$\operatorname{GEm}(n=14)$} & \multicolumn{5}{|c|}{$\operatorname{GEf}(n=14)$} \\
\hline & $M d n$ & $Q_{1}$ & $Q_{3}$ & Min. & Max. & $M d n$ & $Q_{1}$ & $Q_{3}$ & Min. & Max. \\
\hline TMT-A & 37.50 & 30.75 & 44.25 & 23.00 & 85.00 & 40.50 & 22.75 & 47.50 & 21.00 & 55.00 \\
\hline TMT-B & 77.50 & 54.25 & 107.00 & 36.00 & 163.00 & 85.50 & 50.50 & 73.50 & 45.00 & 177.00 \\
\hline $\mathrm{ROCF}-\mathrm{C}$ & 34.00 & 29.87 & 36.00 & 28.00 & 36.00 & 32.25 & 35.75 & 36.00 & 20.50 & 36.00 \\
\hline ROCF-M & 20.25 & 14.25 & 23.75 & 4.00 & 33.00 & 17.50 & 24.37 & 30.50 & 8.50 & 27.00 \\
\hline \multirow{2}{*}{ Neurocognitive tests } & \multicolumn{5}{|c|}{$\operatorname{GCm}(n=14)$} & \multicolumn{5}{|c|}{$\operatorname{GCf}(n=14)$} \\
\hline & $M d n$ & $Q_{1}$ & $Q_{3}$ & Min. & Max. & Mdn & $Q_{1}$ & $Q_{3}$ & Min. & Max. \\
\hline TMT-A & 25.00 & 26.50 & 47.50 & 17.00 & 54.00 & 29.50 & 24.50 & 34.50 & 18.00 & 45.00 \\
\hline TMT-B & 68.50 & 62.50 & 99.75 & 40.00 & 92.00 & 58.00 & 44.75 & 63.75 & 36.00 & 100.00 \\
\hline $\mathrm{ROCF}-\mathrm{C}$ & 36.00 & 35.75 & 36.00 & 34.50 & 36.00 & 36.00 & 36.00 & 36.00 & 34.00 & 36.00 \\
\hline ROCF-M & 30.00 & 12.75 & 22.25 & 21.00 & 33.00 & 36.00 & 28.50 & 34.00 & 18.00 & 36.00 \\
\hline
\end{tabular}

Note. TMT-A (Trail Making Test A), TMT-B (Trail Making Test B), ROCF-C (Rey's complex figure-Copy), ROCF-M (Rey's complex figure-Memory/Recall), GEm (Group of exposed males); GEf (group of exposed females); GCf (Group of control females); GCm (Group of control males), $M d n$ (median), $n$ (number of participants), $Q_{1}\left(1^{\text {st }}\right.$ Quartile), $Q_{3}\left(3^{\text {rd }}\right.$ Quartile), Min. (Minimum), Max. (Maximum). The median (or $50^{\text {th }}$ percentile) is the value that divides the ordered data in half. The lower quartiles ( $1^{\text {st }}$ Quartile) and upper $\left(3^{\text {rd }}\right.$ Quartile) are values below which are a quarter and three quarters of the data, respectively.

Table 2 presents the median, first and third quartiles and the minimum and maximum values obtained on each test by the GEm, GEf, GCm and GCf groups. Table 2 shows that the exposed groups (GEm and GEf) generally presented lower performance on the tests than control groups (GCm and GCf).

Table 3 presents the median, first and third quartiles and the minimum and maximum values for the indices of body composition of the GEm, GEf, GCm and GCf groups. Men in the exposed and control groups generally had higher indices of body water, weight, body fat, lean body mass, WHR, and visceral fat. It is worth mentioning that the body fat of the GEf had a superior minimum and maximum variation (Minimum $=11.60$, Maximum $=43.60)$ to the GEm group (Minimum $=7.50$, Maximum $=33.20$ ).

\section{Inferential Analysis}

Neurocognitive tests. Gas station comparisons (Mann-Whitney U-Test) among the median groups were performed: (1) GEf and GCf; (2) GEm and GCm; (3) GEf and GEm, as shown in Table 4.

The performance of the GEf compared to GCf group was significantly lower in all tests, with a large effect magnitude. The performance of GEm compared to $\mathrm{GCm}$ was also significantly lower in all tests, except for the TMT-B $(p>.05)$. The TMT-A had an average effect magnitude $(U=44.50 ; p=.01 ; r=0.47)$, and a large effect magnitude was observed in the ROCF-Copy $(U=46.50 ; p=.009 ; r=0.50)$ and the ROCF-Recall $(U=29.00 ; p=.001 ; r$ $=0.60)$. 
Table 3

Descriptive Statistics of Median Positions, First and Third Quartiles, Minimum and Maximum Values of Body Composition Indices of the Exposed (GEf, GEm) and Non-Exposed Groups (GCm and GCf)

\begin{tabular}{|c|c|c|c|c|c|c|c|c|c|c|}
\hline \multirow{2}{*}{ Body composition } & \multicolumn{5}{|c|}{$\operatorname{GEm}(n=11)$} & \multicolumn{5}{|c|}{$\operatorname{GEf}(n=10)$} \\
\hline & $M d n$ & $Q 1$ & $Q 3$ & Min. & Max. & $M d n$ & $Q 1$ & $Q 3$ & Min. & Max. \\
\hline Body water (1) & 37.90 & 36.70 & 48.80 & 33.10 & 52.90 & 30.70 & 28.90 & 32.30 & 25.40 & 36.30 \\
\hline Weight (Kg) & 73.50 & 67.90 & 90.70 & 52.60 & 103.80 & 58.60 & 54.30 & 66.70 & 50.80 & 88.90 \\
\hline Body fat (Kg) & 23.70 & 10.90 & 28.00 & 7.50 & 33.20 & 18.30 & 15.60 & 22.50 & 11.60 & 43.60 \\
\hline Lean mass $(\mathrm{Kg})$ & 48.80 & 47.30 & 62.90 & 42.60 & 67.90 & 39.60 & 37.10 & 41.50 & 32.60 & 46.70 \\
\hline WHR (cm) & 0.93 & 0.87 & 0.97 & 0.70 & 1.03 & 0.88 & 0.86 & 0.95 & 0.83 & 1.13 \\
\hline Visceral fat $\left(\mathrm{cm}^{2}\right)$ & 114.00 & 61.50 & 118.80 & 29.20 & 151.80 & 90.90 & 73.90 & 97.30 & 57.60 & 196.60 \\
\hline \multirow{2}{*}{ Body composition } & \multicolumn{5}{|c|}{$\operatorname{GCm}(n=11)$} & \multicolumn{5}{|c|}{$\operatorname{GCf}(n=11)$} \\
\hline & $M d n$ & $Q 1$ & $Q 3$ & Min. & Max. & $M d n$ & $Q 1$ & $Q 3$ & Min. & Max. \\
\hline Body water (1) & 41.90 & 37.30 & 48.30 & 31.3 & 53 & 28.40 & 27.20 & 34.50 & 24.7 & 40.8 \\
\hline Weight (Kg) & 81.80 & 60.10 & 84.30 & 48.10 & 123.10 & 66.00 & 55.00 & 75.80 & 48.70 & 102.50 \\
\hline Body fat (Kg) & 18.50 & 11.30 & 26.80 & 5.40 & 50.90 & 24.00 & 21.10 & 33.30 & 12.40 & 48.00 \\
\hline Lean mass $(\mathrm{Kg})$ & 54.20 & 48.10 & 62.20 & 40.40 & 68.00 & 36.40 & 34.90 & 41.40 & 31.70 & 51.30 \\
\hline WHR (cm) & 0.90 & 0.86 & 0.97 & 0.80 & 1.04 & 0.90 & 0.86 & 0.98 & 0.81 & 0.99 \\
\hline Visceral fat $\left(\mathrm{cm}^{2}\right)$ & 80.30 & 56.50 & 121.20 & 18.60 & 204.6 & 115.90 & 100.00 & 142.00 & 59.40 & 172.10 \\
\hline
\end{tabular}

Note. $n$ (number of participants), $M d n$ (median), $S D$ (standard deviation), GEm (Group of exposed males); GEf (Group of exposed females); GCf (Group of control females); GCm (Group of control males), 1 (liters), Kg (kilograms), cm (centimeters), $\mathrm{cm}^{2}$ (square centimeters).

The GEf took longer to perform the TMT-A and the TMT-B tests compared to the Gem and scored lower in the ROCF elements for the copying and the recall stages, although no significant difference between the groups was observed on any of the tests.

\section{Body Composition}

Body composition analysis showed that the exposed women had lower body water levels compared to exposed men $(U=3.0 ; p<.001)$. The group of exposed women also had less lean body mass compared to the group of exposed men $(U=3.0 ; p<.001)$. Data shown in Table 5.

\section{Correlational Analyzes}

The secondary hypothesis that the performance of men and women could be influenced by body composition measurements was tested. Thus, correlational analyzes (Spearman's Correlation Coefficient) between performance in the neurocognitive tests and body water, weight, lean mass, body fat, WHR and visceral fat measurements were performed, as shown in Table 6.

Table 6 shows that the results of the correlations of the exposed female group indicated a significant positive correlation between the ROCF-Copy test scores and the 
Table 4

Comparison between the Scores of the Study Groups and Control Groups, Presenting the Mann Whitney $U$ Statistic, Level of Significance and Effect Size for Each Test

\begin{tabular}{lccccccccc}
\hline & \multicolumn{4}{c}{ GEf x GCf } & \multicolumn{3}{c}{ GEm x GCm } & \multicolumn{3}{c}{ GEf x GEm } \\
\cline { 2 - 10 } Neurocognitive tests & $U$ & $p$ & $r$ & $U$ & $p$ & $r$ & $U$ & $p$ & $r$ \\
\hline TMT-A & 48.50 & $.02 *$ & 0.43 & 44.50 & $.01 *$ & 0.47 & 89.00 & .68 & 0.08 \\
TMT-B & 39.50 & $.007^{* *}$ & 0.51 & 65.50 & .13 & 0.28 & 90.50 & .73 & 0.07 \\
ROCF-C & 16.00 & $.001^{* *}$ & 0.76 & 46.50 & $.009 * *$ & 0.50 & 79.00 & .38 & 0.19 \\
ROCF-M & 16.5 & $.001 * *$ & 0.71 & 29.00 & $.001 * *$ & 0.60 & 87.50 & .63 & 0.09 \\
\hline
\end{tabular}

Note: TMT-A (Trail Making Test A), TMT-B (Trail Making Test B), ROCF-C (Rey's complex figure-Copy), ROCF-M (Rey's complex figure-Recall), GEm (Group of exposed males); GEf (Group of exposed females); GCf = (Group of control females); GCm (Group of control males); $U$ (Mann Whitney statistics), $r$ (effect size).

$* p<.05 . * * p<.01$.

Table 5

Comparison between the Body Composition Index Scores of the Study Groups and Control Groups, Showing the Mann Whitney $U$ Statistic and Level of Significance

\begin{tabular}{lcccccc}
\hline & \multicolumn{2}{c}{ GEf x GCf } & GEm x GCm & \multicolumn{2}{c}{ GEf x GEm } \\
\cline { 2 - 6 } Body composition & $U$ & $p$ & $U$ & $p$ & $U$ & $p$ \\
\hline Body water (1) & 54.50 & .69 & 55.00 & .72 & 3.00 & $.001^{*}$ \\
Weight $(\mathrm{Kg})$ & 49.00 & .45 & 56.00 & .76 & 54.00 & .01 \\
Body fat $(\mathrm{Kg})$ & 38.00 & .13 & 53.50 & .65 & 58.00 & .87 \\
Lean mass (Kg) & 48.00 & .41 & 54.50 & .69 & 3.00 & $.001^{*}$ \\
WHR (cm) & 48.00 & .41 & 59.00 & .92 & 50.50 & .51 \\
Visceral fat $\left(\mathrm{cm}^{2}\right)$ & 32.00 & .06 & 52.00 & .58 & 58.00 & .87 \\
\hline
\end{tabular}

Note. TMT-A (Trail Making Test A), TMT-B (Trail Making Test B), ROCF-C (Rey's complex figure- Copy), ROCF-M (Rey's complex figure-Recall), GEm (Group of exposed males); GEf (group of exposed females); GCf (Group of control females); GCm (Group of control males); $U$ (Mann Whitney statistics); 1 (liters), Kg (kilograms), cm (centimeters), cm2 (square centimeters).

$* p<.001$.

water measurements $(\mathrm{CC}=0.77 ; p=.005)$, weight $(\mathrm{CC}=-0.86 ; p=.001)$, body fat $(\mathrm{CC}=$ $0.70 ; p=.02)$ and lean body mass $(\mathrm{CC}=0.76$; $p=.007)$.

In relation to the exposed male group, the results showed a positive and significant correlation between the TMT-B scores with the WHR measurements $(\mathrm{CC}=0.73 ; p=.01)$ and visceral fat $(\mathrm{CC}=0.66 ; p=.03)$.

\section{Discussion}

The objective of this study was to verify the neurocognitive performance of men and women with and without a history of chronic exposure 
Table 6

Relationship between Measurements of Body Composition and Scores in the Neurocognitive Tests for the Group of Exposed Females (GEf) and the Group of Exposed Males (GEm)

\begin{tabular}{|c|c|c|c|c|c|c|c|c|}
\hline \multirow{3}{*}{ Body composition } & \multicolumn{8}{|c|}{ GEf } \\
\hline & \multicolumn{2}{|c|}{ TMT-A } & \multicolumn{2}{|c|}{ TMT-B } & \multicolumn{2}{|c|}{ ROCF-C } & \multicolumn{2}{|c|}{ ROCF-M } \\
\hline & $\mathrm{CC}$ & $p$ & $\mathrm{CC}$ & $p$ & $\mathrm{CC}$ & $p$ & $\mathrm{CC}$ & $p$ \\
\hline Body water (l) & -0.29 & .38 & -0.11 & .73 & 0.77 & $.005^{* *}$ & -0.06 & .86 \\
\hline Weight (Kg) & -0.22 & .50 & 0.15 & .65 & 0.86 & $.001 * *$ & 0.16 & .63 \\
\hline Body fat (Kg) & -0.13 & .69 & 0.44 & .18 & 0.70 & $.02 *$ & 0.24 & .48 \\
\hline Lean mass (Kg) & -0.27 & .42 & -0.09 & .79 & 0.76 & $.007 * *$ & -0.09 & .80 \\
\hline WHR (cm) & -0.23 & .50 & -0.02 & .96 & 0.44 & .17 & 0.05 & .88 \\
\hline \multirow[t]{3}{*}{ Visceral fat $\left(\mathrm{cm}^{2}\right)$} & 0.03 & .94 & 0.46 & .16 & 0.58 & .06 & 0.18 & .59 \\
\hline & \multicolumn{8}{|c|}{ GEm } \\
\hline & \multicolumn{2}{|c|}{ TMT-A } & \multicolumn{2}{|c|}{ TMT-B } & \multicolumn{2}{|c|}{ ROCF-C } & \multicolumn{2}{|c|}{ ROCF-M } \\
\hline Body composition & $\mathrm{CC}$ & $p$ & $\mathrm{CC}$ & $p$ & $\mathrm{CC}$ & $p$ & $\mathrm{CC}$ & $p$ \\
\hline Body water (1) & -0.47 & .15 & -0.16 & .65 & 0.34 & .31 & 0.03 & .94 \\
\hline Weight (Kg) & -0.31 & .28 & -0.15 & .62 & 0.13 & .66 & 0.11 & .71 \\
\hline Body fat (Kg) & -0.14 & .69 & 0.52 & .10 & -0.45 & .16 & -0.42 & .20 \\
\hline Lean mass (Kg) & -0.48 & .14 & -0.15 & .67 & 0.29 & .39 & -0.01 & .99 \\
\hline WHR (cm) & 0.08 & .81 & 0.73 & $.01 *$ & -0.58 & .06 & -0.55 & .08 \\
\hline Visceral fat $\left(\mathrm{cm}^{2}\right)$ & -0.02 & .95 & 0.66 & $.03 *$ & -0.52 & .10 & -0.49 & .12 \\
\hline
\end{tabular}

Note. TMT-A (Trail Making Test A), TMT-B (Trail Making Test B), ROCF-C (Rey's complex figure-Copy), ROCF-M (Rey's complex figure-Recall), $\rho$ (Spearman's correlation coefficient of gas stations), 1 (liters), $\mathrm{Kg}$ (kilograms), cm (centimeters), $\mathrm{cm}^{2}$ (square centimeters); TMT (Trail Making Test), ROCF (Rey-Osterrieth complex figure test); CC = correlation coefficient.

$* p<.05 ; * * p<.01$.

to organic solvents. The main hypothesis was to investigate whether exposure would impair neurocognitive performance. The main results confirm the main hypothesis, considering that the chronic exposure to organic solvents altered the neurocognitive performance of exposed women and men in comparison to the control groups.

The results showed that the exposed women in comparison to the non-exposed women obtained a significantly lower performance on all the tasks evaluated by the TMT-A, TMT-B, ROCF-Copy and ROCF-Recall tests. These results demonstrate the possible influence of solvent exposure on the neurocognitive functioning of women.

These data corroborate the study by LoSasso, Rapport, Axelrod, and Whitman (2002) who identified that beauty salon workers [exposed to organic solvents and (Meth) Acrylates] had lower scores on measures of attention and 
cognitive flexibility (TMT-B) in comparison to the control group. It also confirms the findings by Morrow, Robin, Hodgson, and Kamis (2002), who suggest that people exposed to neurotoxic substances generally present a decline in shortterm recall.

However, this result differs from the findings of Parkinson et al. (1990) with women at different degrees of exposure to organic solvents $(n=494)$ compared to non-exposed women ( $n$ $=73$ ), as the authors found no differences for the neurocognitive domains (visuoperceptual functioning, attention/psychomotor integration and motor speed/manual dexterity). It is not possible to make a direct comparison between our study and that by Parkinson et al. (1990), because there are some basic differences. For example, they evaluated women with different categories of exposure to organic solvents, while the present study was conducted with women who had over six months of exposure.

Still, the result of the present study was expected because the central nervous system (CNS) is one of the most vulnerable organs to the effects of solvents, considering that it has a high lipid concentration (Fueta, Fukuda, Ishidao, \& Hori, 2004). Moreover, the data corroborate a study that points out the cumulative effects of chronic exposure (Zavalić et al., 1998).

Exposed men compared to the non-exposed men presented a significantly lower performance in the TMT-A, ROCF-Copy and ROCF-Recall tests, except for the TMT-B (Tables 1 and 2). This result was expected, since similar findings were found by other studies carried out with men (Saygun et al., 2012; Song et al., 2015; Thetkathuek et al., 2015).

These studies have identified that shortterm (memory) recall related to verbal, visual and visuospatial information is one of the most sensitive neurocognitive functions to the effects of solvents. This has even been proven by brain imaging techniques which showed minor activation of regions related to memory recall, such as the striatum, anterior cingulate cortex, pre-frontal and parietal cortex in individuals with chronic exposure to organic solvents (Tang et al., 2011; Visser et al., 2008).

In the present study, no significant difference was found in relation to the cognitive flexibility of the exposed men group compared to the non-exposed group. This may be partly justified because according to Lotti et al. (2015), cognitive impairments related to neurotoxic effects are not well characterized, and some studies have found no differences. For example, Saygun et al. (2012) identified no differences in performance between exposed and non-exposed men in relation to spatial orientation, short-term recall, attention and language evaluated by the Mini Mental State Examination.

The divergences between studies may be related to methodological differences such as the type of measurement used, test administration conditions, or type of statistical treatment applied to the data. Divergences may also be related to differences in exposure parameters such as duration (i.e. chronic, subchronic, acute), type of toxicant agent, frequency and level of concentration (Kim, Jahan, Kabir, \& Brown, 2013), in addition to how the agent is metabolized and the overall susceptibility of the individual's biological system (Klaassen \& Watkins, 2012); all of which makes it difficult to establish the relationship between toxic exposure and neurocognitive changes (Wood \& Liossi, 2005). Nevertheless, the results presented herein indicate the possibility of solvents altering brain structures related to attention, codification of information and shortterm recall in men..

The results showed no differences in the performance of the exposed women compared to the men exposed for the TMT-A, TMT-B, ROCF-Copy and ROCF-Recall tests (Table $2)$. Thus, it was not possible to verify any differences related to sex in neurocognitive performance.

This result corroborates the study by Morrow and Scott (2002) who found no differences between exposed men and women in the tests TMT-A, TMT-B, and ROCF. 
However, Morrow and Scott (2002) did not use a control group as a parameter to verify the proportion of the effects. It is possible that the study by Morrow and Scott (2002) found no differences in outcomes between men and women because the effects of solvents had already been dissipated as the mean time between exposure and assessment was 10 months for men and 9 months for women, while the gas station attendants in the present study were currently performing the profession.

The secondary hypothesis was to investigate the relationship between the results of exposed men and women in the neurocognitive tests with body composition indices. It was expected that the effects of chronic exposure to solvents would impair neurocognitive performance and that the effects would be more pronounced in men than in women due to the differences in body composition (Gochfeld, 2007; Mergler, 2012; Tomicic \& Vernez, 2014; Vahter et al., 2007; Weiss, 2012). In other words, since organic solvents are lipophilic compounds and women generally have higher fat concentration, it was expected that adipose tissue would function as a protective factor in women (Klaassen \& Watkins, 2012).

It is interesting to note that the results of the correlations showed a different pattern of changes related to body composition. Regarding female body composition, a correlation was found only between performance on the ROCFCopy test, which evaluates the process of coding the recall with indexes of water, weight, body fat, and lean mass, while a significant correlation in the exposed men group was only found with performance on mental flexibility (TMT-B), and WHR and visceral fat measurements. In conclusion, the results for women may indicate that with increased weight, body fat, lean mass and visceral fat, the greater the tendency to simplify the drawing, meaning that they observe and encode few details of a complex figure, which would be related to possible alteration in the left hemisphere. Thus, contrary to what was expected, adipose tissue did not function as a protective factor in women, pos- sibly because women had less adipose tissue compared to men.

This result can be explained by Lezak (2004), who identified that patients with lesions in the left hemisphere tend to maintain their recall of the overall structure of the preserved figure, however with loss of details and design simplification; while patients with right hemisphere lesions tend to forget general aspects of the design. The study also showed that people who make an incorrect copy based more on low organization of the data than on a visuospatial ability disorder (more common with lesions in the left hemisphere) can improve their performance in the immediate recall task.

In relation to exposed men, the result partially corroborates the hypothesis that solvents may have a relatively higher distribution volume and be metabolized more slowly in women compared to men (Gandhi et al., 2004). This would mean that higher levels of WHR and visceral fat may interfere with how solvents are distributed and exert their effects on men.

It is important to highlight that both groups presented similar age, schooling, and similar life habits, which increases the probability that the results are related to the effect of solvents.

Literature has argued that neurocognitive changes related to exposure to organic solvents may be related to the genetic polymorphisms in the glutathione S-transferase theta 1 (GSTT1) and glutathione S-transferase mu 1 (GSTM 1) enzymes (Palma, Mozzoni, Mutti, Calzetti, \& Negrotti, 1998), or to a decrease in the neurotrophic factor Serum B-cell lymphoma 2 $(B c l-2)$, derived from a brain that is vulnerable to a variety of toxic effects and involved in cognitive functions (Monat-Descamps \& Deschamps, 2012).

\section{Final Considerations}

In conclusion, this study points out that both men and women can be affected by solvents; however, the way solvents interact with their bodies vary. In women, recall may be further 
impaired by the amount of body water, body fat, and lean body mass; while in men cognitive flexibility may be the most deteriorated due to high WHR and visceral fat indexes. Thus, we can consider that the action of solvents may be more related to body composition indices than to sex.

However, this is an initial study and further research needs to be conducted to clarify the mechanism by which body composition may interfere with the absorption of organic solvents and alter neurocognitive functioning, especially considering the limitations of this study. For example, a small $n$ sample and that only correlations were used did not allow for controlling sociodemographic variables or exposure time.

Thus, longitudinal and experimental studies with animal models are suggested, for example to verify the effects in other cognitive domains and to compare the magnitude of these effects between males and females considering body composition more systematically, as it is difficult to standardize in humans.

These results have important scientific and social implications. They hold the importance of assessing neurocognitive functions early, since changes in these functions may impair work performance and affect several activities of daily living. Thus, they may be predictive of more serious complications such as chronic neurotoxic encephalopathy and neurodegenerative disorders.

\section{References}

Barbosa, I. A. J., Boon, M. Y., \& Khuu, S. K. (2015). Exposure to organic solvents used in dry cleaning reduces low and high level visual function. PLoS ONE, 10(5), e0121422. doi: 10.1371/journal. pone. 0121422

Beasley, T. E., Evansky, P. A., \& Bushnell, P. J. (2012). Behavioral effects of sub-acute inhalation of toluene in adult rats. Neurotoxicology and Teratology, 34(1), 83-89. doi: 10.1016/j. ntt.2011.11.001

Berenguer, P., Soulage, C., Perrin, D., Pequignot, J.-M., \& Abraini, J. H. (2003). Behavioral and neurochemical effects induced by subchronic exposure to $40 \mathrm{ppm}$ toluene in rats. Pharmacology Biochemistry and Behavior, 74(4), 997-1003. doi: 10.1016/S0091-3057(03)00027-3

Berr, C., Vercambre, M. N., Bonenfant, S., Manoux, A. S., Zins, M., \& Goldberg, M. (2010). Occupational exposure to solvents and cognitive performance in the GAZEL cohort: Preliminary results. Dementia and Geriatric Cognitive Disorders, 30(1), 12-19. doi: 10.1159/000315498

Biospace. (2005). InBody 720 User's Manual. Retrieved from http://www.imr-switzerland.org/ downloads/in-body-720-manual.pdf

Blazer, D. G., Yaffe, K., \& Liverman, C. T. (2015). Characterizing and assessing cognitive aging. Washington, DC: National Academies Press. Retrieved from https://www.ncbi.nlm.nih.gov/ books/NBK316201/

Bouchard, B., Blair, S. N., \& Haskell, W. (2012). Physical Activity and Health (2 ${ }^{\text {nd }}$ Ed.). Champaign, IL: Human Kinetics. Retrieved from http://www.humankinetics.com/products/allproducts/physical-activity-and-health-2nd-edition

Dancey, C. P., \& Reidy, J. (2013). Estatística sem Matemática para Psicologia ( $5^{\text {th }}$ Ed.). Porto Alegre, RS: Artmed.

Dancey, C., Reidy, J., \& Rowe, R. (2017). Estatística sem matemática para as ciências da saúde. Porto Alegre, RS: Penso.

Ernstgård, L., Gullstrand, E., Löf, A., \& Johanson, G. (2002). Are women more sensitive than men to 2-propanol and m-xylene vapours? Occupational and Environmental Medicine, 59, 759-767. doi:10.1136/oem.59.11.759

Fueta, Y., Fukuda, T., Ishidao, T., \& Hori, H. (2004). Electrophysiology and immunohistochemistry in the hippocampal ca1 and the dentate gyrus of rats chronically exposed to 1-bromopropane, a substitute for specific chlorofluorocarbons. $\mathrm{Neu}$ roscience, 124(3), 593-603. doi: 10.1016/j.neuroscience.2003.12.025

Gába, A., \& Přidalová, M. (2014). Age-related changes in body composition in a sample of Czech women aged 18-89 years: A cross-sectional study. European Journal of Nutrition, 53(1), 167-176. doi: 10.1007/s00394-013-0514-x 
Gandhi, M., Aweeka, F., Greenblatt, R. M., \& Blaschke, T. F. (2004). Sex differences in pharmacokinetics and pharmacodynamics. Annual Review of Pharmacology and Toxicology, 44(1), 499-523. doi: 10.1146/annurev.pharmtox. 44.101802 .121453

Gleiter, C. H., \& Gundert-Remy, U. (1996). Gender differences in pharmacokinetics. European Journal of Drug Metabolism and Pharmacokinetics, 21(2), 123-128. doi: doi:10.1007/BF03190260

Gochfeld, M. (2007). Framework for gender differences in human and animal toxicology. Environmental Research, 104, 4-21. doi: 10.1016/j. envres.2005.12.005

International Labour Office. (2014, August 25). Safety and health at work: A vision for sustainable prevention. In $X X$ World Congress on Safety and Health at Work 2014: Global Forum for Prevention. Frankfurt, Germany: Author. Retrieved from http://www.ilo.org/wcmsp5/groups/public/@ed_protect/@protrav/@safework/documents/publication/wcms_301214.pdf

Kawai, T., Takeuchi, A., \& Ikeda, M. (2015). Comparison of the exposure-excretion relationship between men and women exposed to organic solvents. Journal of Occupational Health, 57(3), 302-305. doi: 10.1539/joh.14-0240-OA

Kim, K.-H., Jahan, S. A., Kabir, E., \& Brown, R. J. C. (2013). A review of airborne polycyclic aromatic hydrocarbons (PAHs) and their human health effects. Environment International, 60, 71-80. doi: 10.1016/j.envint.2013.07.019

Klaassen, C. D., \& Watkins, J. B., III. (2012). Fundamentos em toxicologia de Casarrett e Doull. Porto Alegre, RS: Artmed.

Lezak, M. D. (2004). Neuropsychological Assessment ( $4^{\text {th }}$ Ed.). New York: Oxford University Press.

Lof, A., \& Johanson, G. (1998). Toxicokinetics of organic solvents: A review of modifying factors. Critical Reviews in Toxicology, 28, 571-650. doi: 10.1080/10408449891344272

LoSasso, G. L, Rapport, L. J., Axelrod, B. N., \& Whitman, R. D. (2002). Neurocognitive sequelae of exposure to organic solvents and (meth)acrylates among nail-studio technicians. Neuropsychiatry Neuropsychology Behavior Neurology, 15(1), 44-55.
Lotti, M., Bleecker, M. L., \& Aminoff, M. J. (2015). Occupational neurology. New York: Elsevier.

Malek, F. A., Möritz, K.-U., \& Fanghänel, J. (2003). A study on specific behavioral effects of formaldehyde in the rat. Journal of Experimental Animal Science, 3(42), 160-170. doi: 10.1016/ S0939-8600(03)80009-3

Mergler, D. (2012). Neurotoxic exposures and effects: Gender and sex matter! Hänninen Lecture 2011. NeuroToxicology, 33(4), 644651. doi: 10.1016/j.neuro.2012.05.009

Monat-Descamps, C., \& Deschamps, F. (2012). Nervous system disorders induced by occupational and environmental toxic exposure. Open Journal of Preventive Medicine, 2(3), 272-278. doi:10.4236/ojpm.2012.23039

Morrow, L. A., \& Scott, A. (2002). Comparison of neuropsychological test scores between men and women with prior exposure to organic solvents. Applied neuropsychology, 9(4), 240-243. doi: 10.1207/S15324826AN0904_7

Morrow, L. A., Robin, N., Hodgson, M. K., \& Kamis, H. (1992). Assessment of attention and memory efficiency in persons with solvent neurotoxicity. Neuropsychologia, 30, 911-922. doi: 10.1016/0028-3932(92)90035-K

National Health Council. (2012). Resolução $n^{\circ} 466$, de 12 de dezembro de 2012. Dispõe sobre diretrizes e normas regulamentadoras de pesquisas envolvendo seres humanos. Retrieved from http://conselho.saude.gov.br/resolucoes/2012/ Reso466.pdf

Occupational Safety and Health Service. (1998). Chronic organic solvent neurotoxicity. Diagnostic criteria. In Occupational Safety and Health Service, Occupational Safety and Health Information Series, p. 1-15. II. New Zealand: Author.

Oliveira, M., Rigoni, M., Andretta, I., \& Moraes, J. F. (2004). Validação do Teste Figuras Complexas de Rey na população brasileira. Avaliação Psicológica, 3(1), 33-38. Retrieved from http:// pepsic.bvsalud.org/scielo.php? script $=$ sci arttext\&pid=S1677-04712004000100004\&lng= pt\&tlng=pt

Palma, G., Mozzoni, P., Mutti, A., Calzetti, S., \& Negrotti, A. (1998). Case-control study of interac- 
tions between genetic and environmental factors in Parkinson's disease. Lancet, 352, 1986-1987. doi: 10.1016/S0140-6736(05)61332-3

Parkinson, D. K., Bromet, E. J., Cohen, S., Dunn, L. O., Dew, M. A., Ryan, C., \& Schwartz, J. E. (1990). Health effects of long-term solvent exposure among women in blue-collar occupations. American Journal of Industrial Medicine, 17(6), 661-675. doi: 10.1002/ajim.4700170602

Reitan, R. (1958). Validity of the Trail Making Test as an indicator of organic brain damage. Perceptual and Motor Skills, 1(8), 271-276. doi: 10.2466/PMS.8.7.271-276

Reitan, R. M., \& Wolfson, D. (1985). The HalsteadReitan Neuropsycholgical Test Battery: Therapy and clinical interpretation. Tucson, AZ: Neuropsychological Press.

Sabbath, E. L., Gutierrez, L.-A., Okechukwu, C. A., Singh-Manoux, A., Amieva, H., Goldberg, M., ...Berr, C. (2014). Time may not fully attenuate solvent-associated cognitive deficits in highly exposed workers. Neurology, 82(19), 1716 1723. doi: 10.1212/WNL.0000000000000413

Saygun, M., Ekici, A., Muluk, N. B., Çakmak, A., Pinar, T., Dag, E., \& Ekici, M. (2012). Effects of long-term low-level solvent exposure on cognitive function. Clinical \& Investigative Medicine, 35(4), E190-E205. Retrieved from http://cimonline.ca/index.php/cim/article/ viewFile/17148/14096

Soldin, O. P., \& Mattison, D. R. (2009). Sex differences in pharmacokinetics and pharmacodynamics. Clinical Pharmacokinetics, 48(3), 143-157. doi: 10.2165/00003088-200948030-00001

Song, H., Yu, I.T.-S., \& Lao, X.Q. (2015). Neurobehavioral effects of occupational exposure to organic solvents among male printing workers in Hong Kong. Archives Environmental Occupational Health, 70, 147153. doi: 10.1080/19338244.2013.828676

Spyker, J. M. (1979). Assessing the impact of low level chemicals on development: Behavioral and latent effects. Federation proceedings, 34(9), 1835-1844. Retrieved from https://www.ncbi. nlm.nih.gov/pubmed/1097268

Tang, C. Y., Carpenter, D. M., Eaves, E. L., Ng, J., Ganeshalingam, N., Weisel, C., ...Fiedler, N.
L. (2011). Occupational solvent exposure and brain function: An fMRI Study. Environmental Health Perspectives, 119(7), 908-913. doi: 10.1289/ehp.1002529

Thetkathuek, A., Jaidee, W., Saowakhontha, S., \& Ekburanawat, W. (2015). Neuropsychological symptoms among workers exposed to toluene and xylene in two paint manufacturing factories in Eastern Thailand. Advances in Preventive Medicine. doi:10.1155/2015/183728

Tomicic, C., \& Vernez, D. (2014). Sex differences in urinary levels of several biological indicators of exposure: A simulation study using a compartmental-based toxicokinetic model. Journal Occupational Environmental Hygiene, 11(6), 377-387. doi: $10.1080 / 15459624.2013 .875180$

Tseng, L. A., Delmonico, M. J., Visser, M., Boudreau, R. M., Goodpaster, B. H., Schwartz, A. V., ...Newman, A. B. (2014). Body composition explains sex differential in physical performance among older adults. The Journals of Gerontology: Series A, 69(1), 93-100. doi: 10.1093/gerona/glt027

Vahter, M., Gochfeld, M., Casati, B., Thiruchelvam, M., Falkfilippson, A., Kavlock, R., ... Coryslechta, D. (2007). Implications of gender differences for human health risk assessment and toxicology. Environmental Research, 104(1), 70-84. doi: 10.1016/j.envres.2006.10.001

Visser, I., Lavini, C., Booij, J., Reneman, L., Majoie, C., Boer, A. G.,... Den Heeten, G. J. (2008). Cerebral impairment in chronic solvent-induced encephalopathy. Annals Neurology, 63(5), 572580. doi: 10.1002/ana.21364

Weiss, B. (2012). The intersection of neurotoxicology and endocrine disruption. NeuroToxicology, 33(6), 1410-1419. doi: 10.1016/j. neuro.2012.05.014

Wood, R. L., \& Liossi, C. (2005). Long-term neuropsychological impact of brief occupational exposure to organic solvents. Archives of Clinical Neuropsychology, 20(5), 655-665. doi: 10.1016/j.acn.2005.01.003

Zavalić, M., Mandić, Z., Turk, R., Bogadi-Sare, A., \& Plavec, D. (1998). Quantitative assessment of color vision impairment in workers exposed 

and Women Exposed to Organic Solvents.

to toluene. American Journal of Industrial Medicine, 3c3(3), 297-304. Retrieved from https://www.ncbi.nlm.nih.gov/pubmed/9481429

Zhong, Z., Zeng, T., Xie, K., Zhang, C., Chen, J., Bi, Y., \& Zhao, X. (2013). Elevation of 4-hydroxynonenal and malondialdehyde modified protein levels in cerebral cortex with cognitive dysfunction in rats exposed to 1-bromopropane. Toxicology, 306, 16-23. doi: 10.1016/j.tox.2013.01.022

Received: $28 / 04 / 2017$

$1^{\text {st }}$ revision: $18 / 02 / 2018$

Accepted: 26/02/2018 distribution, and reproduction in any medium, provided you give appropriate credit to the original author(s) and the source, provide a link to the Creative Commons license, and indicate if changes were made. 